\title{
The Continuing Problem of Asthma in Very Young Children: A Community-Based Participatory Research Project
}

Belinda Wilburn Nelson, PhDa Daniel Awad, MA ${ }^{b}$

Jeffrey Alexander, PhD ${ }^{c}$ Noreen Clark, PhD ${ }^{d}$

\begin{abstract}
BACKGROUND: Asthma is a chronic health condition that has a disproportionate effect on low-income minority children who reside in large urban areas. African American children report significantly higher rates than the general population of children and have more-severe asthma and poorer outcomes. This article describes the prevalence of asthma in a particularly vulnerable group: children aged 2-5 participating in Detroit Head Start programs.
\end{abstract}

METHODS: Health screens were distributed to caretakers of all children attending 6 Head Start agencies. Caretakers of children identified with active asthma symptoms were asked to complete an in-depth phone interview regarding their child's asthma.

RESULTS: Data collected from 3,254 children ( $78 \%$ African American) revealed that $27 \%$ met criteria for probable asthma. Of those with persistent symptoms, $26 \%$ were undiagnosed, and $21 \%$ were untreated. Baseline data $(n=675)$ showed that $95 \%$ had a regular doctor, but $36 \%$ had had no health care visit for asthma in the previous year. Of children with a history of asthma episodes, more than half reported 3 or more episodes in the preceding year. Forty-three percent of caretakers had discussed their child's asthma with Head Start, and 31\% had an asthma action plan on file with Head Start.

CONCLUSIONS: Asthma remains a significant problem in this population, especially for African Americans, as evidenced by high levels of undiagnosed children with persistent symptoms and questions regarding the care they receive. Head Start is a way to reach young children with asthma, but may need help to develop the capacity to assist families.

Keywords: asthma; preschool children; low-income; urban.

Citation: Nelson BW, Awad D, Alexander J, Clark N. The continuing problem of asthma in very young children: a community-based participatory research project. J Sch Health. 2009; 79: 209-215.

Accepted on December 11, 2008

aResearch Investigator, (belindan@umich.edu), Center for Managing Chronic Disease, University of Michigan, 109 Observatory, Ann Arbor, Ml 48109.

bDatabase Manager, (awadd@umich.edu), Center for Managing Chronic Disease, University of Michigan School of Public Health, 109 Observatory, Ann Arbor, Ml 48109.

'Richard Carl Jelinek Professor, (jalexand@umich.edu), Health Services Management \& Policy, University of Michigan School of Public Health, 109 Observatory, Ann Arbor, MI 48109.

dMyron E. Wegman Distinguished University Professor, (nmclark@umich.edu), Director, Center for Managing Chronic Disease, University of Michigan, 109 Observatory, Ann Arbor, Ml 48109 .

Address correspondence to: Belinda Wilburn Nelson, (belindan@umich.edu), Research Investigator, Center for Managing Chronic Disease, University of Michigan, 109 Observatory, Ann Arbor, Ml 48109. 


\section{BACKGROUND}

Asthma is a chronic health condition that has a disproportionate effect on low-income children who reside in large urban areas, a population that is predominantly minority. ${ }^{1-2}$ The racial disparity in asthma prevalence has been well documented, and African American children of all ages report significantly higher rates than the general population of children. ${ }^{3-5} \mathrm{~A}$ review of trends in childhood asthma for the previous 2 decades (1980-1996) reveals that the racial gap in the prevalence has widened and that the largest increase in asthma prevalence has been found in the youngest age group. $^{6}$

Children with asthma who reside in economically disadvantaged urban areas tend to have more-severe asthma ${ }^{2}$ and poorer outcomes over the course of the illness. ${ }^{5}$ Social and physical aspects of the urban environment have been considered as factors that may contribute to the effect of asthma on city-dwelling children, ${ }^{2}$ but there is evidence that, in some low-income children with asthma, parents have problems with treatment compliance and adhering to home management guidelines, ${ }^{7,8}$ factors that clearly affect the course of the illness in children.

The problem of asthma in high-risk children has been addressed primarily by health care providers, with varying levels of success. ${ }^{2}$ Beyond the health care environment, interventions designed to improve asthma management in children tend to focus on school-aged children and, with a few exceptions, do not include very young preschool children. ${ }^{9-11}$ The Head Start environment provides a distinct opportunity to focus on the problem of asthma in very young vulnerable children.

Head Start is a federally funded child development program for economically disadvantaged preschool children (aged 3-5) and their parents. Federal regulations for Head Start participation require that $90 \%$ of the children come from families that meet national guidelines for poverty status. Ten percent of the enrollment spaces are designated for children with disabilities. ${ }^{12}$ The goal of Head Start is to improve cognitive and social skills and prepare low-income children for entrance into the school system. Head Start takes a comprehensive approach to child development, and in addition to addressing the social and environmental factors that affect development, there is an extensive focus on the physical development and health status of each child. ${ }^{12}$ The enrollment process for Head Start includes a comprehensive review of the child's health history. A small percentage of children with asthma are classified with a disability because of the severity of the disease, which is supported by physician documentation of the child's asthma status, but agencies tend to rely primarily on the parent or caretaker report at the time of enrollment to identify a child with asthma.
Head Start, in many ways, appears to be an important venue for assisting with control of asthma, although previous work has shown the current capacity of personnel and organizations to be more limited than desirable. ${ }^{13,14}$ Given that asthma is a chronic disease that can have early onset, the Head Start environment provides an opportunity for early identification of children who are most vulnerable to developing problems with asthma at a critical time in their physical development.

The demographic composition of the Head Start community comprises a group of children who are vulnerable to developing problems with asthma. A few studies provide data on the prevalence of asthma in children in Head Start in diverse sites. ${ }^{15-19}$ Prevalence ranges from a low of $14 \%$ to $22 \%$ for children with diagnosed asthma to a high of $35 \%$ when children with possible asthma are included in the calculations. ${ }^{15-19}$ Symptoms reported for Head Start children without medically diagnosed asthma include wheezing (19\%), cough or bronchitis $(20 \%)$, and nighttime coughing $(23 \%) .{ }^{17}$

National data reveal that the youngest children (aged 0-4) account for the highest rates of emergency department visits and hospitalizations for asthma. ${ }^{20}$ of Head Start children, studies indicate that $30 \%$ to $46 \%$ have visited the emergency department for asthma treatment in the previous year, ${ }^{16,18}$ and hospitalization for asthma care for Head Start children ranged from $9 \%$ to $41 \%{ }^{15,16}$ The use of the emergency department and hospitalization for asthma may be indicative of the severity of children's asthma. It may also reflect how well asthma symptoms are managed and has been linked to a need for further asthma education for parents. ${ }^{21}$ These findings suggest a significant potential for problems with asthma in children in Head Start.

Researchers have examined prevalence, risk factors, and health care patterns of Head Start children with asthma. ${ }^{15-18}$ This article describes the prevalence of asthma and asthma symptoms in a particularly vulnerable group: children aged 2-5 participating in Detroit Head Start programs. It also describes caretakers' reports of health care utilization, communication with health care providers, and the nature of caretakers' interaction with Head Start personnel related to asthma management in the school environment. Caretakers are defined to include the biological parent, foster parent, extended family member, or any adult identified as responsible for the care of the child. Data used are from an initial asthma screening process and from a subsequent baseline assessment of the 675 children identified through screening with diagnosed or probable asthma.

\section{METHODS}

\section{Approach to the Study}

The University of Michigan Institutional Review Board approved all study procedures. The Detroit Head 
Start Asthma study was designed as a community-based participatory project that included the University of Michigan Schools of Public Health and Medicine, Detroit Henry Ford Health System, Detroit Department of Human Services (fiduciary grantee for Head Start), and 6 Detroit Head Start agencies. This study was conducted between September 2003 and December 2005.

The community partners for the study were involved in the development and organization of each critical phase of the project so that data collected would most closely and accurately reflect the experience of the Head Start families. The principles of community-based participatory research ${ }^{22-24}$ were followed in the project. Health coordinators from each Head Start agency and their supervisors played active roles in decision making about study procedure. They had significant involvement in developing the strategy for the screening process and the design and structure of subsequent research activities.

\section{Initial Screening and Subsequent Assessment}

Participants for the study were drawn from families with children enrolled in 6 Detroit Head Start agencies. The standard age for Head Start children is 3-5, but because of citywide concerns about low enrollment the previous year, the Detroit Department of Human Services lowered the age requirement, and children attending Detroit Head Start at the time of screening ranged in age from 2-5. The enrollment capacity for each of the individual Head Start agencies ranged from 350 (smallest agency) to approximately 1000 children (largest agency). Each agency has a number of centers strategically located to serve specific geographical areas of the city. Among the 6 agencies there are a total of 83 centers with the capacity to provide services for approximately 4700 children, but the agencies did not achieve full enrollment, and average daily attendance rates varied widely over the course of the school year for each of the agencies.

Based on estimates provided by the health coordinator of each agency, 4200 surveys were distributed. Caretakers of Head Start children in the 6 agencies were given health packets with an informed consent form and an 11-item screening form. The asthma form was consistent with national asthma guidelines $^{25}$ and included questions about frequency of asthma symptoms (coughing, wheezing, chest tightness, shortness of breath, difficulty breathing with exercise, nighttime severity of symptoms). The survey also inquired about previous-year use of prescription medications for asthma and whether a health professional had ever diagnosed the child. All caretakers who completed and returned the survey $(n=3254)$ were contacted by letter informing them of the outcome of the asthma health survey. Caretakers of children who met criteria for asthma (identified with active symptoms) based on National Asthma Education and Prevention Program (NAEPP) guidelines ${ }^{25}$ also received a list of asthma health care resources in the community and were urged to seek health care assistance.

For the subsequent assessment, caretakers of children who met criteria based on the initial health screen $(n=888)$ were asked to complete an in-depth asthma baseline interview by telephone; 675 consented. The telephone baseline interview instrument was based on previous studies. ${ }^{22,23}$ This 58 -item interview covered the following domains: past-year symptoms, daytime and nighttime severity of symptoms, seasonality of symptoms (all items and criteria for asthma were based on NAEPP Guidelines for Diagnosis and Treatment of Asthma), ${ }^{25}$ asthma self-management and self-regulation behavior, asthma management in the Head Start environment, health care utilization and medication use, and availability of support for the primary caretaker. To measure the caretaker quality of life, a modified version of the Pediatric Asthma Caregiver's Quality of Life Questionnaire was incorporated into the baseline assessment. ${ }^{26}$ Trained interviewers at the University of Michigan completed the baseline assessments, which lasted approximately 30 to $40 \mathrm{mi}-$ nutes. Caretakers who completed the baseline interview received a $\$ 15$ gift card as an incentive for their participation.

Descriptive statistics and frequency distributions were calculated, and chi-square analysis was used for comparison of categories with .05 as the significance level. Data were analyzed using SPSS for Windows (version 14.0; SPSS Inc, Chicago, IL).

\section{FINDINGS}

\section{Characteristics of the Sample}

Screening. Table 1 provides descriptive findings from the initial screening process using the asthma health survey. Consistent with the demographics of the city, the majority of the Head Start children were African American $(78 \%)$, with a smaller percentage of Hispanic or Latino children (17\%). Of the 3254 completed asthma screening forms, 888 children $(27 \%)$ were identified with probable asthma. Of the subgroup of children identified with probable asthma, $68 \%$ had been diagnosed at some time in their life, and $68 \%$ had used prescription medication within the past year. Although African American children represented $78 \%$ of the children who participated in the screening, they accounted for a higher proportion of children who meet criteria for probable asthma $(87 \%)$.

The children identified with probable asthma were also classified for severity based on the frequency of nighttime symptoms. Forty percent of the children identified through the screening process were 
Table 1. Population Characteristics From Initial Asthma Health Screening

\begin{tabular}{lcc}
\hline & $\begin{array}{c}\text { All Children } \\
(\mathbf{N}=\mathbf{3 2 5 4})\end{array}$ & $\begin{array}{c}\text { Identified Children* } \\
(\mathbf{N}=\mathbf{8 8 8})\end{array}$ \\
\hline Gender & $\%$ & $\%$ \\
Male & 49 & 46 \\
$\quad$ Female & 51 & 44 \\
Ethnicity & & \\
African American & 78 & 87 \\
Hispanic/Latino & 17 & 9 \\
Other & 5 & 4 \\
Ever Diagnosed w/ Asthma & & 68 \\
Rx for Asthma in Past Year & & 68 \\
Asthma Severity Status** & & $\%$ \\
Mild Intermittent & & 40 \\
Mild Persistent & & 32 \\
Moderate Persistent & 19 \\
Server Persistent & & 9 \\
Asthma Severity/Diagnosed & & $\%$ \\
Intermittent/ Not Diagnosed & & 6 \\
Persistent/ Not Diagnosed & & 26 \\
Asthma Severity/Rx Status & & $\%$ \\
Intermittent/ No Rx & 21 \\
Persistent/ No Rx & & \\
\hline
\end{tabular}

${ }^{*}$ Children were identified with probable asthma based on any of the following criteria:

\begin{tabular}{|c|c|}
\hline Summary & Criteria \\
\hline Diagnosis \& Symptoms & $\begin{array}{l}\text { Diagnosis and } 1+\text { symptoms } \\
\text { any number of days in past year }\end{array}$ \\
\hline Diagnosis \& Prescription & Diagnosis and prescription \\
\hline Non exercise Symptoms & $\begin{array}{l}3+\text { non exercise symptoms, } \\
\text { each } 5+\text { days in past year }\end{array}$ \\
\hline Exercise Symptoms & $\begin{array}{c}2 \text { exercise symptoms, each } \\
5+\text { days in past year }\end{array}$ \\
\hline Nighttime Symptoms & $\begin{array}{l}\text { Nighttime symptoms } 3+\text { times } \\
\text { per month }\end{array}$ \\
\hline \multicolumn{2}{|c|}{$\begin{array}{l}{ }^{* *} \text { Asthma Severity Classification based on frequency } \\
\text { of nighttime symptoms: }\end{array}$} \\
\hline Mild Intermittent & $0-2$ nights per month \\
\hline Mild Persistent & 3-4 nights per month \\
\hline Moderate Persistent & $5+$ nights per month \\
\hline Severe Persistent & Most nights \\
\hline
\end{tabular}

classified in the mild intermittent and $32 \%$ in the mild persistent asthma categories. Children with moderate persistent and severe persistent classification accounted for $19 \%$ and $9 \%$, respectively. Of the children identified by the asthma health screen, $26 \%$ had persistent symptoms but were not diagnosed. Similarly, of the children identified by the asthma health screen, $21 \%$ had persistent asthma but did not have prescribed medication for their asthma symptoms.

Subsequent Assessment. Ninety-one percent of the caretakers participating in the in-depth assessment were mothers (Table 2), and the majority of caretakers $(72 \%)$ identified themselves as heads of household, which suggests a high rate of single parents caring for children with asthma in this population of
Table 2. Descriptive Characteristics From the Baseline Interview

\begin{tabular}{|c|c|c|}
\hline Primary Caretaker Characteristics & $(\mathrm{N}=675) \%$ & \\
\hline \multicolumn{3}{|l|}{ Relationship to child } \\
\hline Mother (mean age $=30 \mathrm{yr}$ ) & 91 & \\
\hline Father/Grandmother & 7 & \\
\hline Other & 2 & \\
\hline \multicolumn{3}{|l|}{ Educational Level } \\
\hline$<$ High School & 17 & \\
\hline High School/GED & 39 & \\
\hline Vocational Technical/Some College & 35 & \\
\hline College Degree/Advanced Degree & 9 & \\
\hline $\begin{array}{l}\text { Primary Caretaker Is Head of } \\
\text { Household: 'Yes' }\end{array}$ & 72 & \\
\hline $\begin{array}{l}\text { Primary Caretaker Has Support } \\
\text { Person: 'Yes' }\end{array}$ & 61 & \\
\hline \multicolumn{3}{|l|}{$\begin{array}{l}\text { Support Person Relationship } \\
\text { to Primary Caretaker }\end{array}$} \\
\hline Husband/Child's Father & 43 & \\
\hline Child's Grandparent & 27 & \\
\hline Other Relative & 20 & \\
\hline Other General & 10 & \\
\hline Child Asthma Characteristics & $\begin{array}{l}\text { Lifetime } \\
\text { Prevalence: } \\
\text { Ever had } \\
\text { symptom: }\end{array}$ & $\begin{array}{l}\text { Past year } \\
\text { Frequency: } \\
>2 \text { times } \\
\text { per week: }\end{array}$ \\
\hline Asthma Symptoms & $\%$ & $\%$ \\
\hline Cough that won't go away & 60 & 32 \\
\hline Cough with exercise & 56 & 24 \\
\hline Wheeze w/ a cold & 72 & 25 \\
\hline Wheeze w/o a cold & 38 & 10 \\
\hline Wheeze w/ exercise & 42 & 13 \\
\hline Shortness of breath & 37 & 7 \\
\hline \multirow[t]{2}{*}{ Chest heaviness/tightness } & 23 & 2 \\
\hline & $\begin{array}{c}\text { Lifetime } \\
\text { Prevalence: } \\
\text { Asthma Episode }\end{array}$ & $\begin{array}{c}\text { Past year } \\
\text { Frequency: } \\
\text { Asthma Episode }\end{array}$ \\
\hline Asthma Episodes & $\%$ & $\%$ \\
\hline $\begin{array}{l}\text { Has Child Ever Had an Asthma } \\
\text { Episode/Attack: 'Yes' }\end{array}$ & 45 & \\
\hline \multicolumn{3}{|l|}{ Number of Asthma Episodes in Past Year } \\
\hline None & & 9 \\
\hline $1-2$ & & 37 \\
\hline $3-4$ & & 23 \\
\hline $5-6$ & & 13 \\
\hline $7+$ & & 18 \\
\hline
\end{tabular}

Head Start children. However, $61 \%$ of the caretakers indicated that they had someone to help them with the care and management of their child's asthma. The support person identified most often was the husband or the child's father $(43 \%)$, followed by the child's grandparent $(27 \%)$.

The lifetime prevalence for asthma symptoms in the group ranged from a low of $23 \%$ for chest heaviness or tightness to a high of $60 \%$ for coughing that won't go away. Similarly, rates for persistent daytime symptoms ( $>2$ times per week) in the past year ranged from a low of $2 \%$ for chest heaviness or tightness to a high of $32 \%$ for coughing that won't go away. Lifetime prevalence for asthma episodes (an episode of wheezing, tightness, or heaviness in the 
chest or coughing that made it hard to breathe) was $45 \% \quad(n=303)$. A small portion $(9 \%)$ of this group reported no asthma episodes within the past year, $37 \%$ experienced $1-2$ episodes, and more than half of the children with a history of asthma episodes experienced 3 or more episodes in the preceding year. (Table 2).

Queries about health care utilization (Table 3) showed that the majority of children $(95 \%)$ had a regular doctor for their health care. Most caretakers indicated that they had no problems getting medical treatment for asthma $(96 \%)$ or problems with transportation to medical appointments $(92 \%)$, although $36 \%$ of the children had had no regular health care visit for asthma care during the previous year. Forty percent of the children had been to the emergency department for asthma at least once, and 13\% had been hospitalized at least 1 time in the previous year. A small portion of the children $(2 \%)$ required treatment in the intensive care unit for asthma.

An important aspect of health care utilization for caretakers of young children with asthma is the nature of communication with health care providers. Caretakers were asked about aspects of their interaction with health professionals and the extent to which doctors provided information related to the care and management of their child's asthma (Table 4). A significantly larger percentage of caretakers reported that their doctor talked with them than the percentage of caretakers who reported that the doctor gave them written instructions for their child's medication $165 \%$ vs $58 \%$ ), what to do when child is wheezing ( $68 \%$ vs $57 \%)$, how to deal with asthma in the school environment ( $41 \%$ vs $37 \%)$, and information about asthma triggers $(52 \%$ vs $47 \%)$. Additionally, only $37 \%$ reported that the doctor had provided written instructions for an action or care plan for home.

Caretakers were also asked to describe their communication with Head Start personnel related to the care and management of their child's asthma (Table 5 ). We found that only $31 \%$ of caretakers had a written asthma action plan on file with the Head

\section{Table 3. Access to Health Care and Health Care Utilization}

\begin{tabular}{lr}
\hline & $\%$ \\
\hline Child has a regular doctor for their health care: 'Yes' & 95 \\
How hard to get medical treatment for child's asthma & 96 \\
Not too hard/ Not hard at all & \\
How often is transportation to medical appointments & 92 \\
a problem & \\
Hardly ever/ Never & 36 \\
Health Care Utilization in Past Year & 40 \\
$\geq 1$ times-Emergency room & 13 \\
$\geq 1$ times-Hospitalization & 2 \\
$\geq 1$ times-Intensive Care Unit & \\
\hline
\end{tabular}

Table 4. Communication With Health Care Provider

\begin{tabular}{lcccc}
\hline & $\begin{array}{c}\text { Doctor Had Doctor Gave } \\
\text { Discussion } \\
\text { With } \\
\text { Caretaker }\end{array}$ & $\begin{array}{c}\text { Written } \\
\text { Instructions } \\
\text { to Caretaker }\end{array}$ \\
\hline Asthma Management Topic: & $\%$ & $\%$ & $X^{2}$ p-value \\
\hline Child's medication & 65 & 58 & .000 \\
What to do when child is wheezing & 68 & 57 & .000 \\
Dealing with asthma at school & 41 & 37 & .000 \\
Triggers or things that start asthma & 52 & 47 & .000 \\
\hline
\end{tabular}

Start center, but $43 \%(\mathrm{n}=290)$ had discussed their child's asthma and the asthma medication with Head Start personnel. Of the subgroup of caretakers who indicated that they had talked with Head Start regarding their child's asthma, a variety of queries focused on the potential ways that Head Start assisted caretakers of children with asthma; $17 \%$ of these caretakers revealed that someone at Head Start helped them talk with their child's doctor, 15\% received assistance from Head Start personnel on how to manage asthma, $12 \%$ were shown how to use a diary card to track asthma symptoms, $17 \%$ received information on asthma triggers, and $15 \%$ reported that Head Start personnel helped them obtain an asthma action plan from their child's doctor.

Last, most caretakers indicated that they were very confident $(59 \%)$ or fairly confident $(25 \%)$ in the ability of Head Start personnel to provide proper care if their child had problems with asthma.

\section{DISCUSSION AND CONCLUSIONS}

These data were collected with the help of-and have benefitted from-the experience of Head Start professionals, to ensure accuracy and relevance of

Table 5. Asthma Management in the Head Start Environment

Caretaker/Parent has

Asthma Action Plan on file w/Head Start center

Discussed asthma/medications w/Head Start staff

Do caretakers/parents have someone at Head

Start who helps them: $(n=290)$

Talk with child's doctor about asthma

Manage child's asthma

Use diary to track child's asthma symptoms

Know what triggers child's asthma symptoms

Obtain written asthma plan from doctor

Arrange transportation to doctor

Make visits/appointment to doctor

Formulate questions for doctor

Understand child's health insurance coverage

How confident are caretakers that Head Start knows

what to do if child's has a problem with asthma

Very confident

Fairly confident

Not at all/ Not too confident/ Don't know
$\%$ 
methods employed. These data constitute a reasonably reliable picture of asthma in Detroit Head Start children. The picture is worrisome. The percentage of children identified by the health screen with probable asthma but who were also undiagnosed and had untreated asthma exceeded one-quarter of the sample. Furthermore, the children identified with probable asthma were likely to have persistent disease. Although Medicaid-related health care provisions enabled most children to have access to a physician, slightly more than one-third had had no regular health care visit for asthma in the previous year, $40 \%$ had been to the emergency department during that time for asthma, and one-third of children with persistent symptoms had no prescription medicine for the condition. At a minimum, these data call into question the system for identifying and following up with children at risk. These findings suggest that, in low-income areas, asthma continues to be a serious problem for young children, especially African Americans. Reaching and serving such children requires using the most accessible, relevant, and appropriate channels available.

The prevalence of asthma symptoms among Head Start children suggests that Head Start staff members will encounter a significant number of children who may need assistance. The data show that caretakers had high hopes that Head Start personnel could handle asthma problems, but few families had been assisted by Head Start to connect with health care or had been advised how to manage children's health problems more effectively. Most had no asthma action plan on record at the center. The relatively high level of confidence reported by the caretakers is not commensurate with the percentage who had taken steps to address the care of their child's asthma while in the Head Start center (discussed their child's asthma or had asthma action plans on file with the Head Start center). This disparity between caretaker perception and actual planning for asthma management in the Head Start environment suggests that caretakers and Head Start personnel may benefit from further education on how to provide optimal care and asthma management for young children.

Anecdotal data from interviews conducted with key Head Start personnel (in preparation for this study) provide information on their perceptions of what is needed to enhance their ability to help children with asthma. They identified the need for more general asthma knowledge (eg how to identify symptoms, types of medications used for asthma, how to administer asthma medication), prevention and management of asthma emergencies, and the need to reduce anxiety in Head Start staff related to caring for children with asthma. Increasing caretaker asthma awareness and caretaker participation in educational activities was also identified as an important aspect of improving the ability of Head Start to help children with asthma.

The ability of Head Start to respond to the needs of these children is a vital component of their goals for children's comprehensive health and well-being. Head Start personnel have unique access to caretakers of children with asthma and are in critical support roles. Their status as early childhood educators (many personnel are former Head Start parents with close ties to the community) may confer special influence with Head Start caretakers, who are predominantly young mothers. ${ }^{27}$ Head Start personnel who are properly trained and knowledgeable about asthma in preschool children have the potential to be a beneficial asset to the health of children with asthma, particularly those who are undiagnosed and untreated. Head Start organizations are worthy of assistance with capacity-building programs designed to enhance their ability to help families with asthma control. Interventions designed to enhance asthma management in the Head Start environment should include Head Start personnel, as well as caretakers in education goals and intervention activities.

\section{REFERENCES}

1. Crain EF, Weiss KB, Bijur PE, Hersh M, Westbrook L, Stein REK. An estimate of the prevalence of asthma and wheezing among inner-city children. Pediatrics. 1994;94(3):356-362.

2. Federico MJ, Liu AH. Overcoming childhood asthma disparities of the inner-city poor. Pediatr Clin North Am. 2003;50(3):655-675.

3. Centers for Disease Control and Prevention. Asthma Prevalence Percents by Age, United States: National Health Interview Survey. 2003.

4. Evans IR. Asthma among minority children: a growing problem. Chest. 1992;101:368S-371S.

5. Halfon N, Newacheck PW. Childhood asthma and poverty: differential impacts and utilization of health services. Pediatrics. 1993;91(1):56-61.

6. Akinbami LJ, Schoendorf KC. Trends in childhood asthma: prevalence, health care utilization, and mortality. Pediatrics. 2002; $110(2): 315-322$.

7. Celano M, Geller RJ, Phillips KM, Ziman R. Treatment adherence among low-income children with asthma. J Pediatr Psychol. 1998; 23(6):345-349.

8. Warman KL, Silver EJ, McCourt MP, Stein REK. How does home management of asthma exacerbations by parents of inner-city children differ from NHLBI guideline recommendations? Pediatrics. 1999;103(2):422-427.

9. Findley SE, Levitt D, Hanus E, et al. Helping Your Child Live With Asthma: A Parents' Handbook. New York, NY: Asthma Basics for Children, Northern Manhattan Community Voices, Mailman School of Public Health, Columbia University;2003.

10. Wilson SR, Latini D, Starr NJ, et al. Education of parents of infants and very young children with asthma: a developmental evaluation of the Wee Wheezers program. J Asthma. 1996;33(4): 239-254.

11. Wilson SR, Fish L, Page A, Starr-Schneidkraut N. Wee Wheezers: An Educational Program for Parents of Children With Asthma Under the Age of Seven. Palo Alto, Calif:American Institute of Research; 1994.

12. US Department of Health and Human Services, Administration for Children and Families, Administration on Children, Youth 
and Families. Head Start Bureau. Head Start Program Performance Standards and Other Regulations;2001.

13. Walders N, McQuaid E, Dickstein S. Asthma knowledge, awareness, and training among Head Start staff and Early Head Start staff. J School Health. 2004;74(1):32-34.

14. Huss K, Winkelstein M, Calabrese B, et al. Asthma management practices and education needs of Head Start directors and staff. J School Health. 2002;72(8):329-333.

15. Laudebache P, Nicolosi R, Reece S, Saucedo K, Volicer B, Richards T. Asthma in Head Start children: prevalence, risk factors, and health care utilization. Pediatr Nurs. 2001;27(4):396-399.

16. McGill KA, Sorknesss CA, Ferguson-Page C, et al. Asthma in noninner city Head Start children. Pediatrics. 1998;102(1):77-83.

17. Slezak JA, Persky VW, Kviz FJ, Ramakrishnan V, Byers C. Asthma prevalence and risk factors in selected Head Start sites in Chicago. J Asthma. 1998;35(2):203-212.

18. Vargas PA, Simpson PM, Wheeler G, et al. Characteristics of children with asthma who are enrolled in a Head Start program. J Allergy Clin Immunol. 2004; 1 14:499-504.

19. Walsh K, Kelly C, Morrow A. Head Start: A setting for asthma outreach and prevention. Fam Commun Health. 1999;22(1): 28-37.

20. Centers for Disease Control and Prevention. Surveillance for Asthma-United States, 1980-1999. Morb Mortal Weekly Rep. 51(SS1); March 2002.
21. Wasilewski Y, Clark NM, Evans E, Levison MJ, Levin B, Mellins RB. Factors associated with emergency visits by children with asthma: implications for health education. Am J Publ Health. 1996;86(10):1410-1415.

22. Clark NM, Brown R, Joseph CL, et al. Issues in identifying asthma and estimating prevalence in an urban school population. J Clin Epidemiol. 2002;55(9):870-881.

23. Nelson BW, Valerio MA, Houle C, Brown RW, Brown CR, Clark NM. Working with a Head Start population with asthma: lessons learned. J School Health. 2006;76(6):273-275.

24. Israel BA, Schulz AJ, Parker EA, Becker AB, Allen AJ, Guzman JR. Critical issues in developing and following community based participatory research principles. In: Minkler M $\&$ Wallerstein N, eds. Community-Based Participatory Research for Health. San Francisco, Calif: Jossey-Bass; 2003:53-75.

25. NAEPP Expert Panel Report. Guidelines for the Diagnosis and Management of Asthma-Update on Selected Topics 2002. Bethesda, Md: National Institute of Health; June 2002.

26. Juniper EF, Guyatt GH, Feeny DH, Ferrie PJ, Griffith LE, Townsend M. Measuring the quality of life in the parents of children with asthma. Qual Life Res. 1992;5:27-34.

27. Lacy GL. Head Start Social Services: How African American mothers use and perceive it. In: Bruchey S, ed. Children of Poverty, Studies in the Effects of Single Parenthood, The Feminization of Poverty and Homelessness. New York, NY: Garland; 1999. 